\title{
AN ASSESSMENT OF COST ESCALATION IN BUILDING CONSTRUCTION PROJECT
}

\author{
A. Nazif ${ }^{1,}{ }^{*}$, A. K. Mustapha ${ }^{2}$ and F. Sani ${ }^{3}$

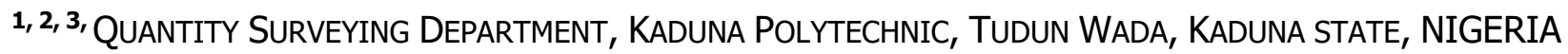 \\ Email addresses: ${ }^{1}$ aminanzif@yahoo.co.uk, 2 zeemnina@yahoo.com, \\ 3 sanifaisal490@gmail.com
}

\begin{abstract}
Estimating of cost for building construction projects with minimum error at the conceptual stage of project development is quite essential for planning. This study seeks to evaluate factors responsible for cost escalation of building construction projects. Questionnaires were administered to examine and assess these factors. Subsequent/y, the mean score value of each factor was determined. In addition, Correlation and Linear regression analyses were used to establish the relationship between these factors. Factors responsible for cost escalation in projects were examined as well as the impact of those factors, and occurrence of those factors on project cost. The result of the analysis showed that, the most agreed factors responsible for project cost escalation were; inadequate supervision, irregular payment, and design error, having high mean values of 4.25, 4.20, and 4.15, respectively. Also, correlation analysis result established that the factors responsible for cost escalation and the impact of cost escalation had significant $R$ and $R^{2}$ of 0.81 and 0.70 respectively. Addressing these factors would go a long way in reducing the escalation of building project cost. Never the less, an effective cost management strategy is absolutely necessary to safeguard and sustain the construction industry.
\end{abstract}

Keywords: cost escalation, building project, construction, regression analysis

\section{INTRODUCTION}

The construction industry plays a vital role in the welfare of most economies; this includes providing shelter, infrastructure, and employment [1]. Similarly, the construction sector and construction activities are considered to be one of the major sources of economic growth, development and economic activities [2].

In Nigeria, the construction industry plays a dominant role in the economic activities of the country. The construction industry accounts for about $60 \%$ of the Nation's capital investment and $30 \%$ of the Gross Domestic Product (G.D.P) [3]. Furthermore, the construction industry is said to have contributed about half of the total stock of fixed capital investment in the Nigerian economy [4]. The construction industry also generates employment opportunities, which place it second to the Government in the employment of labour [5].
However, there are various problems associated with the construction industry, particularly during the construction project process, amongst them is cost escalation.

Cost escalation is the increase in the amount of money required to construct a given project above the initially budgeted sum. It also arises, if the actual cost of construction is in excess of the originally estimated amount [6]. Some projects are being completed at a cost higher than the initial budge, hence, creating an unsuccessful project delivery [7]. It was also established that poor contract could be attributed to the manner in which the contract was awarded. In some cases, projects are awarded to the lowest bidder, which results into various degrees of problems [8]. Some of these low bidders may have inadequate management skills and have less regard for contract plans; cost control; overall site management; and resource 
allocation. In some situations, added cost has been established to have obvious negative implications to the key stakeholders in particular, and the industry at large. To the client, high cost implies added costs over those initially agreed upon at the onset, resulting in less return on investment. The added costs are passed on to the end users as high rental/lease costs or prices. Also, these added costs will result in the inability to deliver value-for-money by consultants; this could tarnish their reputation and lead to loss of confidence reposed on them by clients. On the side of the contractor, there could be loss of profit through penalties for noncompletion, and negative comments that could jeopardize his/her chances of winning further jobs, if at fault [9]. Cost management system is a process that should be carried out throughout the lifecycle of a project, from the inception to the final completion and final payment to the contractor. In the light of this, the timelines and cost effectiveness of various operations and decisions carried out will determine to an extent the magnitude of cost that could be saved on the project [10]. This study aims at identifying and examining the factors responsible for cost escalation.

\section{MATERIALS AND METHODS}

For this study, questionnaires were administered to respondents that work in various consulting and contracting organizations that are involved in various construction projects. A total of 100 questionnaires were administered and 80 were returned. The questionnaires returned comprised of 60 and 20 questionnaires from consulting and contracting firms, respectively. In addition, 64 of the respondents handled both public and private projects, 12 respondents handled private projects, while, 4 respondents handled public projects. The questionnaires were administered to professionals including; Quantity surveyors, Structural Engineers, Architects, and Builders. The respondents comprised of top level management, middle level management and lower level management staff.

Subsequently, statistical mean scores and standard deviation were used to analyse the data acquired, the Likert's five - point scale was used to analyse the responses of the respondents.

The formula for mean is:

$$
M=\frac{\sum f x}{\sum f}
$$

Where: $f x=$ Total frequency and $f=$ Frequency

\subsection{Regression Analysis}

The relationship between the factors responsible for cost escalation, the impact of the factors responsible for cost of escalation, and the occurrence of factors responsible for cost escalation were determined using Correlation and Linear regression analysis. The regression analyses used for this study are as follows;

\subsubsection{Correlation coefficient (R)}

Measures the linear association between two variables. Usually, values of the correlation coefficient are between -1 and +1 . A correlation coefficient of +1 identifies that two variables are significantly related in a positive linear logic; a correlation coefficient of -1 identifies that two variables are significantly related in a negative linear sense, and a correlation coefficient of 0 indicates that there is no linear relationship between the two variables [8].

\subsubsection{Linear Regression Analysis (LR)}

The general form of LR analysis is as follows:

$Y_{i}=\beta_{0}+\beta_{1} X_{1 i}+\varepsilon_{i}$

Where $Y$ is the dependent variable (predictant), $\beta_{0}$ is a constant coefficient, $\beta_{1}$, is referred to as regression coefficients while $X_{1}$, (predictor) is the independent variable and $\varepsilon$ is the residual error (difference between observed and predicted values) [12].

\subsubsection{Coefficient of Determination $\left(R^{2}\right)$}

$\mathrm{R}^{2}$ is used to signify how well the model results fit to the observed data points; it can also be used to indicate the similarity between the model tendency and the observed concentration [12].

$$
R^{2}=\left[\frac{\sum_{i=1}^{n}\left(O_{i}-\bar{O}\right)^{2} \cdot\left(P_{i}-\bar{P}\right)}{n \cdot \sigma_{0} \cdot \sigma_{p}}\right]^{2}
$$

Where, $\mathrm{n}$ is total number of annual measurements, $\mathrm{P} i$ is predicted values, $\mathrm{O} i$ is observed values, $\bar{O}$ is the mean observed values, $\bar{P}$ is mean of the predicted values, $\sigma_{p}$ is standard deviation of the predicted values, and $\sigma_{o}$ is standard deviation of the observed values. 
Table 1: Five Likert Rating Scale

\begin{tabular}{lccccc}
\hline & Strongly Agree & Agree & Undecided & Disagree & Strongly Disagree \\
\hline Grade Point & 5 & 4 & 3 & 2 & 1 \\
Range & $4.5-5.0$ & $3.5-4.4$ & $2.5-3.4$ & $1.5-2.5$ & $0.5-1.4$ \\
\hline
\end{tabular}

\section{RESULTS AND DISCUSSION}

\subsection{Mean score Analysis}

\subsubsection{Factors Responsible for Cost Escalation in Building Construction Projects}

From Figure 1, the main factors responsible for cost escalation in building construction projects were assessed using mean score and Likert rating scale. The factors agreed by the respondents were inadequate supervision with the highest mean value of 4.25 and a ranking of $1^{\text {st }}$, followed by irregular payment and fraudulent practice and kickbacks which have the same ranking of $2^{\text {nd }}$ and a mean value of 4.2 , next was differing site condition and design error having the same mean value of 4.15 and a ranking of $4^{\text {th }}$, respectively. While the least favorable factor is adjustment of prime cost sum with mean value of 3.05 and a ranking of $17^{\text {th }}$, as shown in Figure 1. This is in agreement with previous study that suggested that fraudulent practices and kickbacks occasioned by greed are perpetuated by some major players in the construction industry [10].

\subsubsection{Level of Occurrence of Factors Responsible for Cost Escalation}

Figure 2 showed that the irregular payment is a frequently occurring factor in building construction projects with a mean value of 4.05 and a ranking of $1^{\text {st }}$, followed by inadequate supervision with mean value of 3.70 and a ranking of $2^{\text {nd }}$, lack of cost control has a mean value of 3.65 and a ranking of $3^{\text {rd }}$, and fluctuation of price of materials and contract management having the same mean value of 3.45 and a ranking of $4^{\text {th }}$ respectively. While the least factor is wastages on site which had a mean value of 2.60 and a ranking of $17^{\text {th }}$. Therefore, the data obtained highlighted the factors that bring about cost escalation in building construction projects.

\subsubsection{Impact of Factors Responsible for Cost Escalation}

Based on the findings in Figure 3, the most significant factors that are responsible for cost escalation are design error, extensive variation, wrong method of estimation, irregular payment, fluctuation, differing site condition, fraudulent practice, and kickbacks with mean value of 4.00 , $3.80,3.70,3.65,3.65,3.65,3.65$ and a ranking of $1^{\text {st }}, 2^{\text {nd }}, 3^{\text {rd }}, 4^{\text {th }}$, respectively.

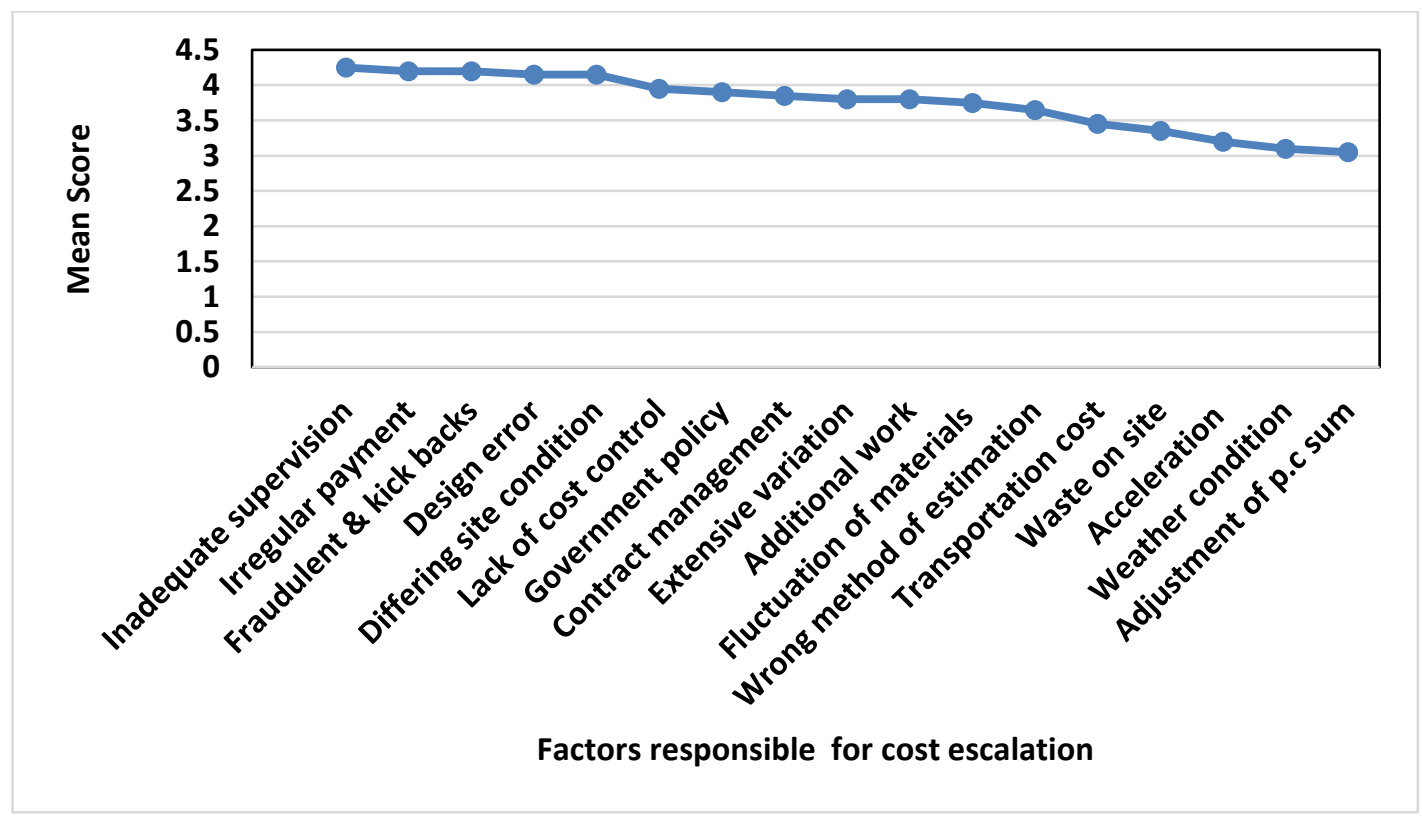

Figure 1: Factors responsible for Cost escalation 


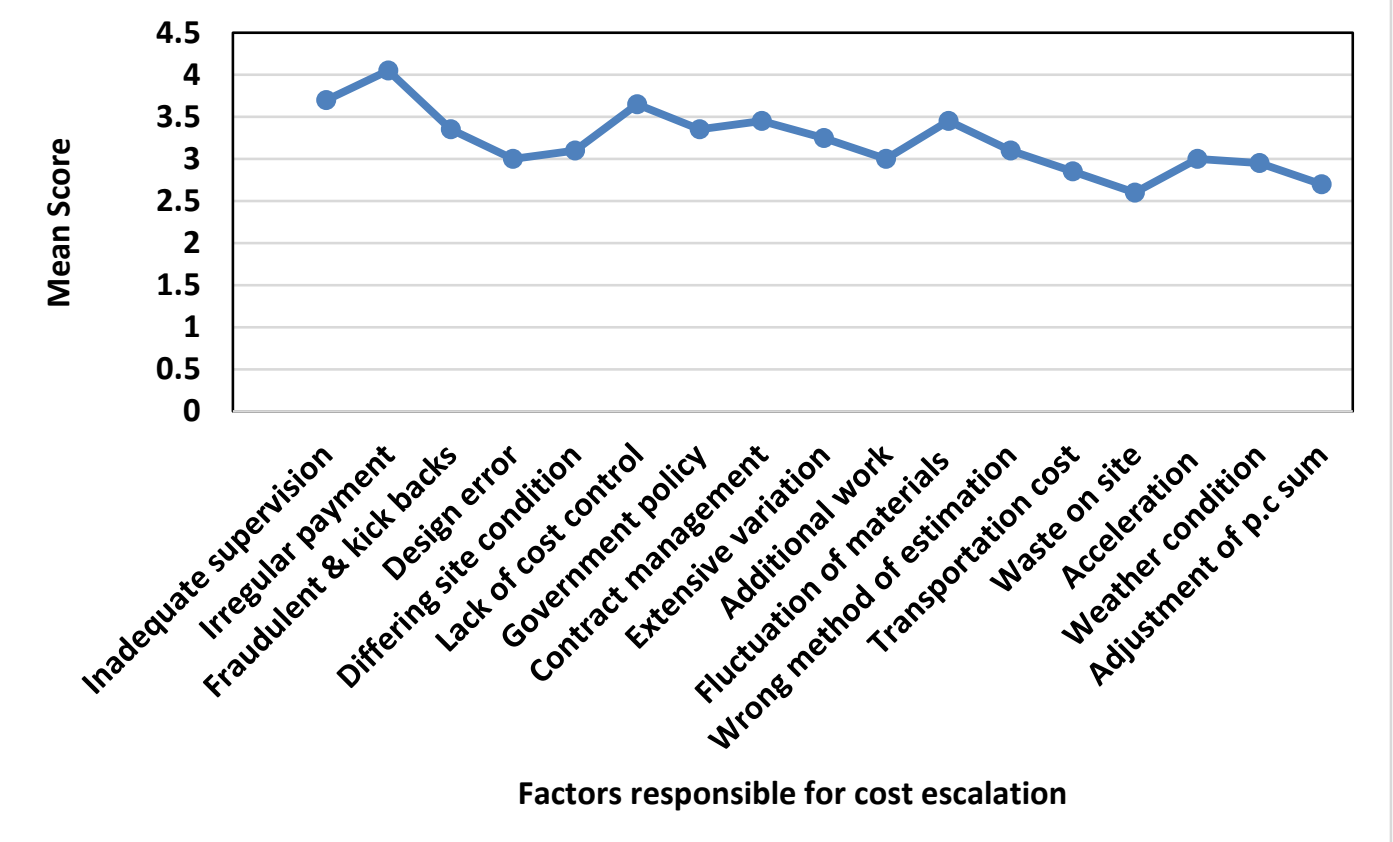

Figure 2: Occurrences of Factors Responsible for Cost Escalation

While the most insignificant and least factor is adjustment of prime cost sum with mean value of 2.50 and a ranking of $17^{\text {th }}$. In a previous study it was also established that design error was one of the factors responsible for cost escalation [12].

Furthermore, the analysis showed that quite a number of cost escalation factors have been agreed upon by the respondents in various professions. The result also revealed that some factors have significant level of occurrence and influence in building construction project; this includes irregular payment, inadequate supervision, and lack of cost control and fluctuation of price of materials. Similarly, the result further indicated the most significant factors which need to be focused more carefully on so as to mitigate the rise in cost of building construction projects. These factors include design error, extensive variation, and wrong method of estimation, irregular payment, fluctuations, differing site condition and inadequate supervisions. In a previous study irregular payment was also ascertained as a factor that causes cost escalation in projects [13].

\subsection{Regression Analysis Result}

\subsubsection{Relationship between Factors and Impact of factors}

Based on the linear regression model in Figure 4 and Table 2, a significant relationship was established for factors responsible for cost escalation and impact of factors responsible for cost escalation, having $R$ and $R^{2}$ result of 0.81 and 0.70 , respectively. These results established that the factors that have influence on cost escalation and their impact are significantly related. Also, the linear regression analysis established that the factors that influence cost escalation can explain their impact on cost with $70 \%$ certainty. Also, the P-value was $<0.00$ confirming that the analysis is significant. Moreover, the correlation result for factors responsible for cost escalation and occurrence of factors responsible for cost escalation was significant, having $R$ result of 0.7 , however, the linear regression result was not significant, having $\mathrm{R}^{2}$ result of 0.45 . The $\mathrm{P}$-value was 0.01 which is $>0.00$ suggesting that the relationship between the variables was not significant. Also, the analyses result for Occurrence of factors responsible for cost escalation and impact of factors responsible for cost escalation were not significant both having $R$ and $R^{2}$ of 0.47 and 0.23 , respectively. The $P$-value also confirmed the insignificance of the analyses with a P-value of $>0.06$ which is $>0.00$.

\section{CONCLUSION}

The study assessed factors responsible for cost escalation in building construction project by identifying factors that leads to cost escalation and examining the factors that lead to escalation of cost in building construction projects.

Based on the study findings, the major factors responsible for cost escalation obtained from the 
professionals in the construction industry were; inadequate supervision, irregular payment, design error, differing site condition, and lack of cost control. Furthermore, it was determined that irregular payment, inadequate supervision, lack of cost control and fluctuation were the most frequently occurring factors in building construction that causes cost escalation. In addition, the result also revealed that, design error, extensive variation, wrong method of estimation, fluctuation of price of materials and irregular payment were the most significant factors leading to cost escalation in building construction project. Also, Regression analysis established a significant relationship between factors responsible for cost escalation and impact of cost escalation, having $R$ and $R^{2}$ result of 0.81 and 0.70 , respectively.

Furthermore, the correlation result of factors responsible for cost escalation \& occurrence of cost escalation was also significant, having an $\mathrm{R}$ result of 0.7 , however, the linear regression result was not significant, having $\mathrm{R}$ result of 0.45 . More so, the regression analyses result for occurrence of cost escalation and impact of cost escalation was not significant, both having $R$ and $R^{2}$ of 0.47 and 0.23 , respectively.

Escalation of construction cost can be reduced to a bearable level by adhering to the following; at the construction stage, a clear and thorough client brief should be taken from inception of project to avoid or minimize excess variation. Others include; prompt payment of certificate, and employment of competent contractors and consultants. Also, constant cross checking of estimates based on updated price information to avoid any wrong estimate. More so, proper assessment of details should be done before embarking on a project and lastly, professional integrity.

Cost escalation in building construction projects can be solved or minimized when the factors examined in this study have been addressed; it will go a long way in minimizing cost escalation of building construction projects.

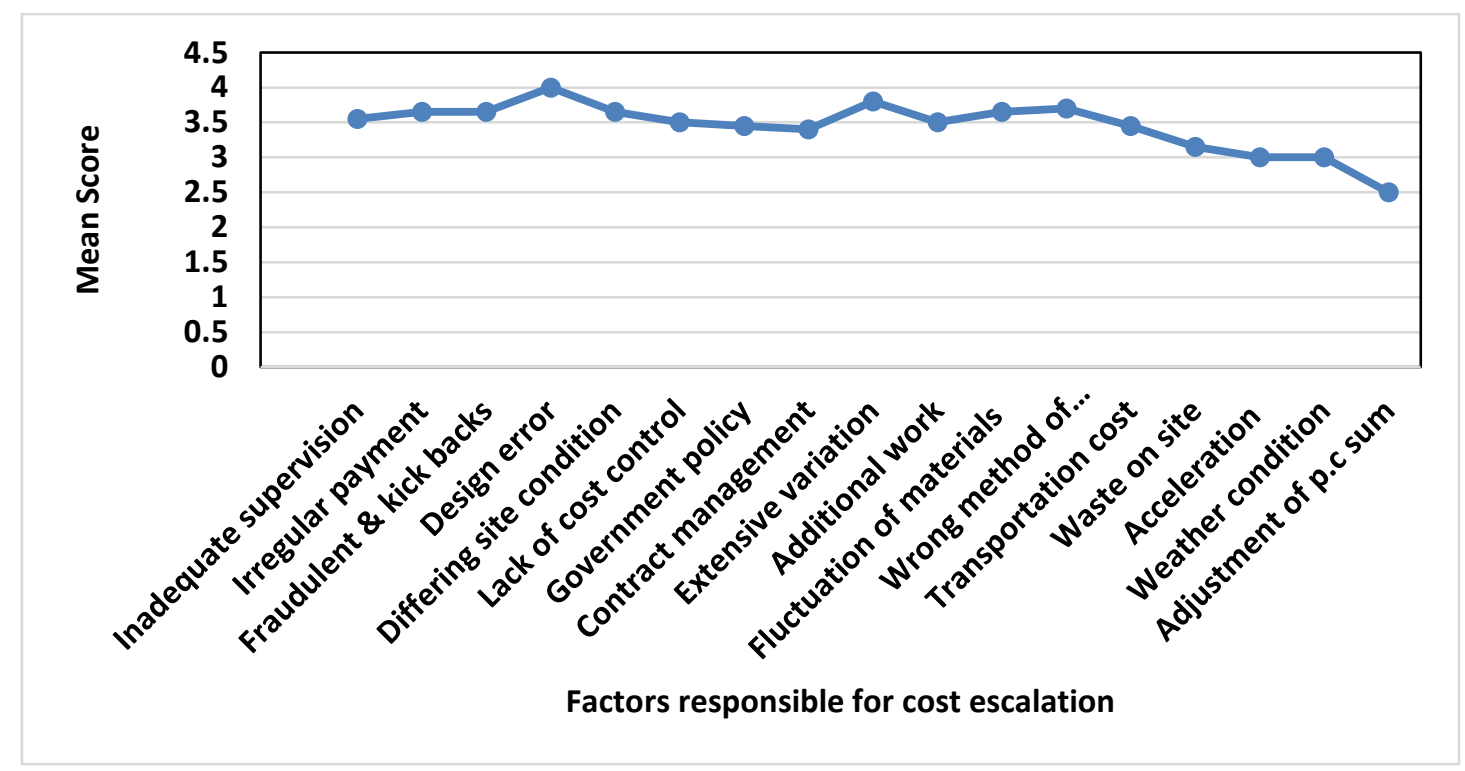

Figure 3: Impacts of Factors Responsible for Cost Escalation

Table 2: Regression Analyses Result

\begin{tabular}{llll}
\hline Analyses & $\begin{array}{l}\text { Factors Responsible and } \\
\text { Impact of Factors } \\
\text { Responsible for Cost } \\
\text { Escalation }\end{array}$ & $\begin{array}{l}\text { Factors Responsible and } \\
\text { Occurrence of Factors } \\
\text { Responsible for Cost } \\
\text { Escalation }\end{array}$ & $\begin{array}{l}\text { Occurrence and Impact of } \\
\text { Factors Responsible for } \\
\text { Cost Escalation }\end{array}$ \\
\hline $\begin{array}{l}\text { Linear } \\
\text { regression } \\
\text { model }\end{array}$ & $\mathrm{y}=0.878 x+0.7011$ & $\mathrm{y}=0.7051 x+1.4811$ & $\mathrm{y}=0.4713 x+1.5565$ \\
$\mathrm{R}$ & 0.81 & 0.70 & 0.47 \\
$\mathrm{R}^{2}$ & 0.70 & 0.45 & 0.23 \\
$\mathrm{P}$-value & 0.000 & 0.01 & 0.06 \\
\hline
\end{tabular}




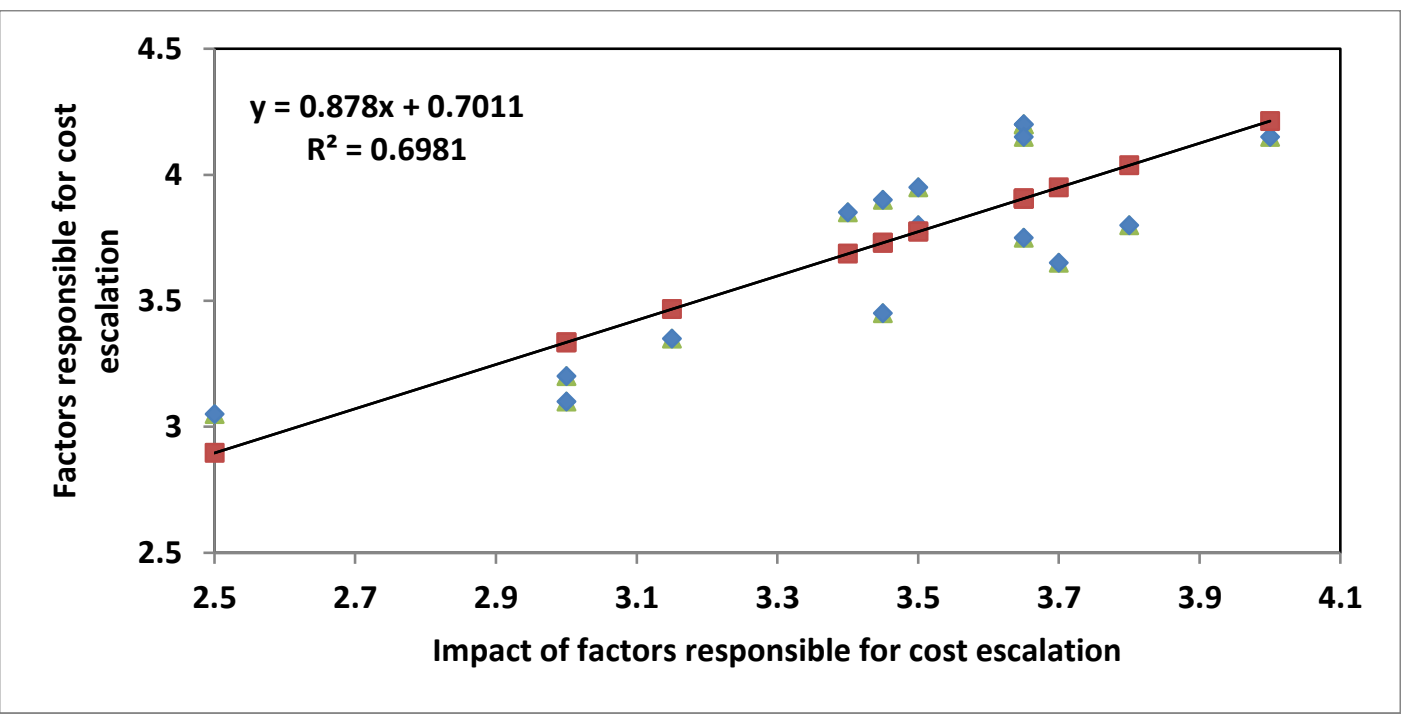

Figure 4 Linear Regression Model for Factors Responsible and Impact of Factors Responsible for Cost Escalation

\section{REFERENCES}

[1] Anaman, K.A. and Osei-Amponsah, C. Analysis of the Causality Links Between the Growth of the Construction Industry and the Growth of the Macro Economy in Ghana Construction Management and Economics, 25(9),951-961, 2007.

[2] Khan, R.A. Role of Construction Sector in Economic Growth: Empirical Evidence from Pakistan Economy. First International Conference on Construction in Developing Countries (ICCIDC-I) "Advancing and Integrating Construction Education, Research \& Practice" August 4-5, Karachi, Pakistan, 2008.

[3] Olowo - Okere, E.G. Problems of Construction Management in Nigeria', Paper presented to the workshop on National Construction Policy, ASCON, Badagry - Lagos, Nigeria, 1988.

[4] Olaloku, F.A. The Quantity Surveyor, the second tier Foreign Exchange Market and the Construction Industry in Nigeria; Options and Challenges', Construction in Nigeria. Journal of the Federation of Building and Civil Engineering Contractors in Nigeria 4 (I) 4-8, 2007.

[5] Hussein, A.A. Construction and the National Economy. The Nigerian Quantity Surveyor. 2021, 1991.

[6] Majid, M. Z. A., Zakaria, W. Z., Lamit, H., Keyvanfar, A., Shafaghat, A., and Bakti, E. B.
Construction Information Systems for Executive Management in Monitoring Work Progress. Journal of Advanced Science Letter. 15(PP): 169-171, 2012.

[7] Anosike, P. Nigerian Groans Under High Cost of Building Material. The Daily Sun. 38-39, $6^{\text {th }}$ April 2009.

[8] Mansfield, N.R. , Ugwu, O.O. and Doran, T. Causes of Delay and Cost Overruns in Nigeria Construction Projects. International Journal of Project Management 12 (4) 254 - 260, 2011.

[9] Mbachu J. I. C. and Nkado, R.N. Reducing Building Construction Costs; The Views of Consultants and Contractors. COBRA, 2004.

[10] Kerzner, H. C. Project Management. $6^{\text {th }}$ Edition. John Wiley and Sons. Incorporated Canada, 2005.

[11] Hox, J. J., Moerbeek, M., and Van de Schoot, R. Multilevel Analysis: Techniques and Applications $3^{\text {rd }}$ Edition. Routledge Press. 2017.

[12] Devi, V. and Jegan R. Cost Escalation in Construction Projects International Journal for Research in Applied Science \& Engineering Technology 5(1), 271-277, 2017

[13] Ogunlana. S., Krit, P., and Vithool, J. Construction Delays in a Fast-growing Economy; Comparing Thailand with other Economies. International Journal of Project Management 14 (1) 37 - 45, 2013. 